\title{
A comunicação para a conservação: 0 caso do movimento em prol da APA da escarpa Devoniana (Paraná, Brasil)
}

\author{
COMmUnication FOR CONSERVATION - A CASE STUDY OF THE MOVEMENT IN FAVOR OF THE DEVONIAN ESCARPMENT ENVIRONMENTAL \\ PROTECTION AREA (PARANÁ STATE, SOUTHERN BRAZIL)
}

\author{
Nair F. B. Mochiutti, Gilson B. Guimarães \\ Programa de Pós-Graduação em Geografia, Universidade Federal de Santa Catarina, \\ S/N, 88040-900, FLoRIANóPOLIS, SC, BRASIL \\ Departamento de Geociências, Universidade Estadual de Ponta Grossa, Av. General Carlos Cavalcanti, 4748, 84030-900, Ponta Grossa, PR, Brasil \\ E-MALL: FERNANDAMOCHIUTTI@YAHOO.COM.BR, GILSONBURIG0@GMALL.COM
}

Abstract: The Devonian Escarpment Environmental Protection Area is a sustainable protected area created in 1992, devoted to the protection of the natural and cultural heritage of the Campos Gerais in Paraná State, Southern Brazil, and also of the transition zone between the First and Second Paranaense Plateaus. It includes examples of Brazilian geoheritage, such as the Devonian Escarpment, Buraco do Padre sinkhole, and the Vila Velha sandstones. In 2016, the Law Project 527/2016, which proposes a reduction of almost $70 \%$ of its original area, began its legal process in the Legislative Assembly of Paraná. A synergy between the scientific, academic and conservationist community, and the general population led to several successful communication actions. Among these were: creation of a social network page in defense of the protected area, production of scientific outreach material, explanation of the relevance of the protected area and reasons to reject the project, news reports in various media, lectures on the protected area and the Law Project, and production of a documentary film with key participation by artists from Paraná State. As a consequence, the Law Project had its approval possibilities greatly diminished, and the level of knowledge by the population, regarding the natural and cultural heritage of the Devonian Escarpment Environmental Protection Area, increased significantly.

\section{Manuscrito:}

Received: VIII Simpósio Nacional de Ensino e História de Ciências da Terra / EnsinoGE0-2018. Geociências para Todos

Accepted: 14/01/2018

Citation: Nair F. B. Mochiutti, Gilson B. Guimarães. 2018. A comunicação para a conservaçãa: o caso do movimento em prol da APA da Escarpa Devoniana (Paraná, Brasil). Terræ Didatica, 14(4):455-462. URL: http://www.ige.unicamp. br/terraedidatica/.

Palavras-chave: Comunicação, APA, Escarpa Devoniana, Campos Gerais.

Linha temática: Comunicação e Divulgação das Geociências.

\section{Introdução}

A região dos Campos Gerais do Paraná é detentora de um rico patrimônio natural, que congrega elementos excepcionais tanto da geodiversidade como da biodiversidade (Melo et al. 2007). As fisionomias de campos naturais, matas com araucária e relictos de cerrado dividem a paisagem com canyons, escarpamentos, lajeados, cachoeiras, relevos ruiniformes, sítios fossilíferos e cavernas, habitats de uma infinidade de espécies de animas.

A história natural dessa região integra também o capítulo do homem e seu patrimônio cultural, com destaque para a existência de inúmeros sítios arqueológicos com pinturas rupestres e para o legado do tropeirismo, ciclo econômico que está na origem da maioria dos municípios que compõem os Campos Gerais.
Visando proteger esse conjunto de características naturais e culturais foram implantadas gradualmente nessa região do estado várias unidades de conservação (UCs), tanto de proteção integral como de uso sustentável, de âmbito federal, estadual e municipal. Dentre elas está a Área de Proteção Ambiental (APA) da Escarpa Devoniana, criada em 1992 com 392.363,38 ha distribuídos em 12 municípios (Moreira \& Rocha 2007), sendo a maior UC do Estado do Paraná. Uma atualização de sua base cartográfica foi apresentada em 2014 pelo Instituto Ambiental do Paraná e o Instituto de Terras, Cartografia e Geociências, adicionando 608 ha às suas dimensões (Silva 2014).

Desde sua implantação esta UC de uso sustentável enfrenta grandes desafios para equilibrar a balança entre a exploração de seus recursos naturais e a conservação dos mesmos. O capítulo mais 
recente destes conflitos se iniciou no ano de 2016, quando passou a tramitar na Assembleia Legislativa do Estado do Paraná (ALEP) o Projeto de Lei n ${ }^{\circ}$ 527 , de autoria de três deputados, que propõe a redução de aproximadamente $70 \%$ da área original da APA da Escarpa Devoniana.

Motivações de ordem econômica dão o tom a essa proposta de alteração dos limites da APA, um projeto que tem sido marcado pelo caráter antidemocrático e por inúmeras falhas técnicas e legais, questionado inclusive pela Ordem dos Advogados do Brasil e pelo Ministério Público Estadual.

Tão logo o projeto de lei veio a público, um movimento contrário à redução da APA da Escarpa Devoniana se instaurou, inicialmente nas redes sociais, mas se estendendo posteriormente para diferentes meios de comunicação, motivando ainda a realização de palestras e debates sobre o tema. Essa mobilização, fruto desse processo de comunicação, freou o trâmite do PL-527/2016 no legislativo do Paraná e promoveu a divulgação de temas ambientais e científicos para toda a população, com importante destaque para o campo das Geociências.

O objetivo desse trabalho é apresentar um levantamento das diferentes iniciativas de comunicação e divulgação do conhecimento científico que surgiram em resposta ao PL-527/2016 e analisar os desdobramentos para conservação desta importante unidade de conservação paranaense.

\section{A APA da Escarpa Devoniana}

As Áreas de Proteção Ambiental são unidades de conservação de uso sustentável, ou seja, procuram compatibilizar o uso de parte dos recursos naturais disponíveis com a conservação dos mesmos, buscando sua perenidade (Brasil 2000). Esse uso é disciplinado no plano de manejo da UC por meio do zoneamento ecológico econômico, elaborado de acordo com as condições locais bióticas, abióticas, urbanísticas, agropastoris, extrativistas, culturais e outras (Brasil 1988).

Por ter este perfil, essa categoria de UC permite a ocupação do homem e suas atividades, podendo conter tanto áreas privadas como públicas, englobando cidades e áreas industriais.

A APA da Escarpa Devoniana envolve segmentos de 12 municípios na região dos Campos Gerais do Paraná (Lapa, Porto Amazonas, Balsa Nova, Palmeira, Campo Largo, Ponta Grossa, Carambeí, Castro, Tibagi, Piraí do Sul, Jaguariaí- va e Sengés), que juntos somam cerca de 720.000 habitantes, sendo Ponta Grossa o $4^{\circ}$ município com maior contingente populacional do estado (IBGE 2017). A região é cortada por importantes rodovias e ferrovias e se destaca no cenário nacional por sua produção agrícola, leiteira e madeireira, e também pela presença do maior parque industrial do interior do Paraná (Weirich Neto \& Rocha 2007, Jasper 2015).

Esse conjunto de atividades econômicas divide espaço com um riquíssimo patrimônio natural, uma convivência que a APA da Escarpa Devoniana busca harmonizar. De acordo com o decreto de criação da UC, no Art $1^{\circ}$, seu objetivo é "(...) assegurar a proteção do limite natural entre o Primeiro e o Segundo Planaltos Paranaenses, inclusive faixa de Campos Gerais, que se constituem em ecossistema peculiar que alterna capões da floresta de araucária, matas de galerias e afloramentos rochosos, além de locais de beleza cênica como os canyons e de vestígios arqueológicos e pré-históricos" (Paraná 1992).

Como está explícito em sua denominação e em seu objetivo de criação, esta UC tem como uma 'linha mestra' a estrutura de relevo denominada Escarpa Devoniana, um ressalto topográfico que marca o limite entre o Primeiro e o Segundo Planalto do Paraná. Segundo Souza e Souza (2002), esse escarpamento se estende por $260 \mathrm{~km}$ entre os estados de São Paulo e Paraná e apresenta amplitudes entre 100 e $200 \mathrm{~m}$ e altitudes médias em torno de 1.100-1.200 m.

A Escarpa se desenvolveu em arenitos da Formação Furnas, unidade devoniana da Bacia do Paraná, e embora receba a adjetivação alusiva à idade das rochas que a sustenta, é muito mais recente. Sua origem e evolução estão relacionadas a processos tectônicos, iniciados com a separação do Gondwana e abertura do Oceano Atlântico (Jurássico) e erosivos, que atuaram de forma contínua ao longo do Cretáceo e Cenozoico (Souza \& Souza 2002, Melo et al. 2007).

Por suas características e espetacularidade a Escarpa Devoniana faz parte do conjunto de Sítios Geológicos e Paleobiológicos do Brasil (SIGEP 80, Souza \& Souza 2002), o que the confere o reconhecimento como um patrimônio geológico nacional.

Outros elementos da geodiversidade se destacam na faixa de exposição da Formação Furnas e unidades geológicas associadas dentro da APA da Escarpa Devoniana, representando o patrimônio geológico paranaense e do país. São exemplos 
os arenitos de Vila Velha, a furna do Buraco do Padre, a Lagoa Dourada, o Salto Santa Bárbara e o Canyon Guartelá, todos também cadastrados junto à plataforma do SIGEP (Guimarães, Liccardo \& Piekarz 2013).

Em termos de biodiversidade, a região dos Campos Gerais é considerada uma Área Prioritária para a Conservação, Utilização Sustentável e Repartição de Benefícios da Biodiversidade Brasileira dentro do bioma Mata Atlântica (MMA 2004), para a qual é recomendada a criação de Unidades de Conservação e inventários biológicos.

Além da APA da Escarpa Devoniana, outras UCs cobrem a região dos Campos Gerais, sendo as mais conhecidas o Parque Estadual do Monge (Lapa), Parque Estadual de Vila Velha (Ponta Grossa), Parque Nacional dos Campos Gerais (Ponta Grossa, Castro e Carambeí), Parque Estadual do Guartelá (Tibagi), Parque Estadual do Cerrado (Jaguariaíva), todas de proteção integral. A APA engloba todas as UCs citadas, funcionando como uma matriz que conecta essas áreas protegidas.

A existência dessas UCs, além de resguardar o patrimônio natural, gera benefícios para toda a sociedade, por meio dos serviços ambientais, geração de renda através da atividade turística e arrecadação do ICMS Ecológico. Segundo Guimarães et al. (2017), a APA da Escarpa Devoniana, além de prestar um conjunto de serviços geossistêmicos (zona de recarga do Aquífero Furnas, solos que sustentam a atividade agrícola, operação do ciclo hidrológico, laboratório para o ensino das Geociências), também é responsável pela geração de cifras advindas de ICMS Ecológico para os municípios que integram essa UC, alcançando cerca de 7 milhões em 2017, segundo dados do Instituto Ambiental do Paraná.

\section{0 PL-527/2016}

Apesar de criada em 1992, a APA da Escarpa Devoniana só teve seu Plano de Manejo e seu Zoneamento Ecológico Econômico publicados em 2004, sendo que seu Conselho Gestor foi estabelecido quase dez anos depois, em 2013. A morosidade na concretização destas etapas, aliada a uma fiscalização deficiente por parte dos órgãos competentes, custou caro ao patrimônio natural dos Campos Gerais. Segundo dados levantados por pesquisadores da Universidade Estadual de Ponta Grossa, nos últimos 25 anos houve uma severa conversão dos sistemas naturais em siste- mas produtivos, passando de uma proporção de 61\%/39\% em 1992 para 33\%/67\% em 2017 (Guimarães et al. 2017).

Vista como um entrave ao desenvolvimento econômico do estado, principalmente da região onde se encontra, recentemente a APA da Escarpa Devoniana foi alvo de um Projeto de Lei que prevê a redução de sua área original em cerca de $70 \%$. Encabeçado por três deputados, o PL-527 começou a tramitar na ALEP em 2016, sem o conhecimento do Conselho Gestor da UC e embasado em um estudo feito por uma empresa ligada ao agronegócio.

Os objetivos desta redução passam pela exclusão de setores urbanizados e áreas utilizadas para a produção agropecuária e de silvicultura de larga escala (soja, milho, pinus etc.) de dentro da APA. Como consequência se conseguiria uma ampliação de áreas para agricultura intensiva, cultivo de árvores exóticas e outras atividades de grande impacto que não se adequam ao Zoneamento Ecológico Econômico proposto no Plano de Manejo da UC em 2004.

A desafetação ou redução dos limites de uma unidade de conservação é um mecanismo previsto na Lei do SNUC, desde que respeite os parâmetros legais e que seja fundamentado em estudos técnicos promovidos pela equipe de gestão da UC e com participação da comunidade científica e população local (Scalco \& Gontijo 2017). A adoção de uma medida como esta deve ter caráter excepcional e favorecer a gestão e conservação da UC, mas infelizmente tem sido utilizada com frequência no Brasil e em outras regiões do mundo, raramente para fortalecer a política de conservação (Mascia et al. 2014).

Segundo Symes et al. (2016), áreas protegidas de maiores dimensões, como costumam ser as APAs, relacionadas a um grande contingente populacional, são mais suscetíveis a processos de desafetação, redução e reclassificação. A disponibilidade de uma área e seus recursos potenciais fazem com que o custo de oportunidade seja muito maior que o de outros usos da terra, motivando a adoção de mecanismos de alteração das UCs.

O que está acontecendo com a APA da Escarpa Devoniana segue essa tendência, evidenciando um completo desconhecimento (ou pura desconsideração) dos objetivos de uma unidade de conservação de uso sustentável e uma visão simplista de desenvolvimento econômico, que desconsidera a participação dos sistemas naturais preservados.

\begin{tabular}{c|c|c|c|c|c|}
\hline (C) Terrae Didat. & Campinas, SP & v.14 & n.4 & p. 455-462 & out./dez. 2018 \\
\hline
\end{tabular}




\section{Estratégias de comunicação em prol da APA da Escarpa Devoniana}

O processo de criação de áreas protegidas, na maioria das vezes, parte do meio científico, tem apoio dos órgãos ambientais competentes e acaba sendo referendado pelo poder legislativo. Embora a participação popular seja desejada e esteja prevista nesse trâmite, ela nem sempre acontece, ou é deficiente. Como consequência, há um distanciamento da sociedade em geral das unidades de conservação e um desconhecimento sobre a função das mesmas ou mesmo sobre o que de fato elas protegem.

A ausência de participação popular no processo de criação de uma UC consequentemente se repetirá num processo de desafetação ou redução da mesma e, sem mobilização da sociedade, é grande a chance de que tal processo tenha sucesso.

Segundo o MMA (2015), o fortalecimento da cidadania ambiental e uma efetiva participação popular na gestão da bio e geodiversidade passam pela comunicação e pela educação ambiental. A colaboração de profissionais ligados à ciência e ao ensino, assim como entidades do terceiro setor, é fundamental nessas ações, construindo pontes entre a sociedade e o conhecimento e na mobilização de diversos atores.

O movimento que se iniciou em resposta ao PL-527/2016 partiu principalmente da comunidade científica, acadêmica e de Organizações não Governamentais, além de representantes do legislativo estadual.

Esses atores foram responsáveis pela concepção e implantação de diferentes estratégias de comunicação que visaram divulgar para a sociedade informações sobre a APA da Escarpa Devoniana, sua importância ambiental, social e econômica e as ameaças às quais ela está submetida. As principais iniciativas e seus desdobramentos serão apresentadas a seguir.

\subsection{Redes sociais e petição pública}

Para o mal e para o bem, as redes sociais representam uma ferramenta poderosa de mobilização e alcance de pessoas. A facilidade e a rapidez na divulgação de informações, o efeito multiplicador por meio dos compartilhamentos e a possibilidade de organizar ações em caráter emergencial são indispensáveis hoje em qualquer que seja a causa.

A criação de uma página em uma das redes sociais mais utilizadas hoje no mundo foi uma das primeiras ações contra o PL-527/2016. Com o nome "Movimento contra a redução da APA da Escarpa Devoniana" a página funciona como um canal para divulgação de reportagens, textos, vídeos e imagens relacionados à APA e ao trâmite do projeto de lei, assim como da agenda de atividades, que incluíram até agora aulas públicas, palestras, debates, reuniões, passeatas, panfletagens e eventos culturais. A página também é utilizada para compartilhar materiais sobre temas como unidades de conservação, preservação ambiental, biodiversidade, geodiversidade, crimes ambientais, etc. Conta hoje com cerca de 3.000 manifestações de aprovação ('curtidas') e pouco mais de 3.000 seguidores.

A partir da adesão de novas entidades e pessoas ao movimento e até mesmo da criação de outras páginas em redes sociais, foi criada uma logomarca, visando unificar as ações sob uma mesma bandeira (Fig. 1).

Paralelamente à criação da página foi elaborada uma petição pública, que além de ser divulgada na rede social, foi também compartilhada via correio eletrônico, aplicativo de mensagens de celular e veiculada na mídia local da região dos Campos Gerais. Com o título "Assembleia Legislativa do Paraná: queremos que o projeto 527/2016 seja rejeitado e arquivado", a petição alcançou 8.390 assinaturas e segue ativa.

\subsection{Material impresso}

Uma das principais necessidades levantadas durante as reuniões entre as instituições envolvidas no movimento em prol da APA da Escarpa Devoniana foi a de divulgar o conhecimento sobre a UC e seu patrimônio natural. $\mathrm{O}$ objetivo foi explicar conceitos e terminologias usados comumente no meio científico e acadêmico, mas estranhos ou

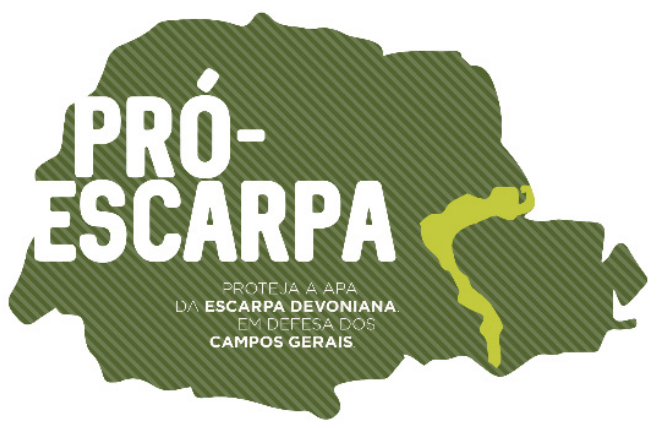

Figura 1. Logomarca do movimento contra a redução da APA da Escarpa Devoniana 
sem significado imediato para a maior parte da população.

Para tanto, foram elaborados materiais como panfletos, cartilhas e volantes (Fig. 2), ilustrados e com textos concisos abordando os seguintes pontos:

- O que é uma APA?

- O que é a Escarpa Devoniana?

- Campos Gerais do Paraná

- Ameaças à APA

- Por que somos contra o PL-527/2016

- Turismo e conservação na APA

Esses materiais foram impressos e disponibilizados também em formato digital, distribuídos em escolas, universidades, durante aulas públicas, palestras e em uma audiência pública promovida pela ALEP no município de Ponta Grossa, em março de 2017, que reuniu cerca de 1000 pessoas.

Os temas foram abordados de maneira didática e sem perder o rigor científico. Buscou-se ainda valorizar a ideia de pertencimento e identidade territorial, a fim de que os leitores incorporassem o patrimônio natural e cultural da APA como seus.

\subsection{Reportagens em jornais, revistas e TV}

Outros canais importantes para veiculação de informações sobre a APA e sua situação de vulnerabilidade ambiental foram jornais e revistas (em versões impressas e digitais), blogs de notícias e reportagens na televisão, principalmente inserções em telejornais, mas também com programas específicos.

Em termos ambientais, a APA da Escarpa Devoniana e a proposta de redução de seus limites foram com certeza o assunto mais abordado nos veículos acima citados, no Paraná, durante o ano de 2017. Foram no mínimo 50 textos com caráter científico, investigativo e de denúncia, elaborados por jornalistas, pesquisadores, professores, técnicos, nomes ligados à conservação da natureza e ao direito ambiental, e dezenas de inserções nos telejornais das principais emissoras do estado.

O programa Meu Paraná, exibido todos os sábados pela afiliada da Rede Globo no Paraná (RPC), dedicou duas edições de quase 20 minutos cada à APA. Uma delas contextualizando a unidade de conservação e o seu rico patrimônio natural, além dos aspectos culturais e das ameaças que vem

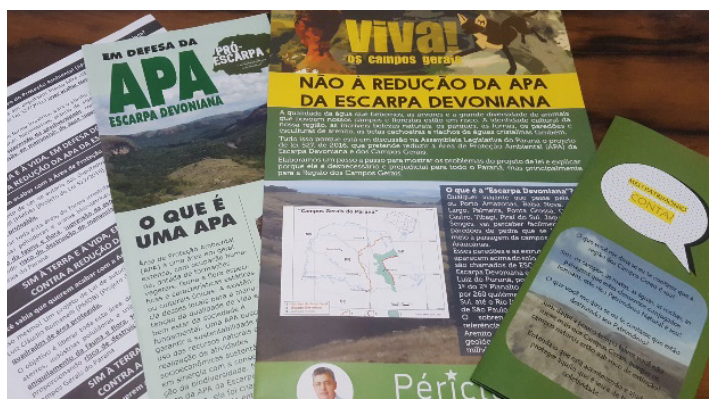

Figura 2. Material impresso sobre a APA, suas características naturais e ameaças

enfrentando desde a sua criação, e outra específica sobre o patrimônio espeleológico e arqueológico dentro da área da APA.

Além da repercussão que a causa ganhou por meio da exposição midiática, um ponto importante foi a divulgação para a sociedade do conhecimento científico produzido nas últimas décadas sobre: o patrimônio geológico dos Campos Gerais; a biodiversidade dos campos nativos e florestas com araucárias; recursos hídricos superficiais e subterrâneos; a evolução do uso da terra e a fragmentação da paisagem; cavidades naturais subterrâneas e; turismo em áreas naturais.

\subsection{Documentário e trilha sonora}

A luta pela APA da Escarpa Devoniana sensibilizou também o mundo das artes. Um curta-metragem produzido pelo Observatório de Justiça e Conservação, entidade ambiental com sede em Curitiba, faz em 15 minutos um apanhado geral sobre a APA e as ilegalidades e incoerências do PL-527/2016. Com o título "Os Últimos Campos Gerais", o curta já teve 360.000 visualizações desde seu lançamento, em outubro de 2017.

O vídeo foi vinculado a um sítio na internet (http://osultimoscamposgerais.com.br/), onde as pessoas têm acesso a mais informações sobre o tema e podem enviar um e-mail aos deputados estaduais do Paraná, solicitando a rejeição do projeto de lei. Até o dia 15 de fevereiro deste ano 152 mil mensagens já haviam sido enviadas ao legislativo paranaense (OJC 2018).

O documentário é embalado por uma canção especialmente criada para essa causa. "Pare. Preste Atenção!" foi interpretada por mais de 40 artistas e seu clipe já teve 1 milhão e 320 mil visualizações. Recentemente o clipe da música recebeu a tradução para a linguagem brasileira de sinais e legendas em 
português (OJC 2018).

Essa "dobradinha" artística fez com que o movimento em prol da APA da Escarpa Devoniana ultrapassasse os limites paranaenses, mobilizando apoiadores em todo território nacional.

\subsection{Palestras, debates e aulas públicas}

Uma das estratégias adotada pelo 'Movimento contra a redução da APA da Escarpa Devoniana' foi a realização de exposições orais para públicos diversos. Em alguns casos como palestras únicas ou aulas públicas, mas também integrando debates, facilmente a audiência atingida alcança a cifra de centenas de pessoas.

Principalmente em eventos acadêmicos em universidades ou palestras para escolas do Ensino Básico, houve também intervenções para plateias específicas, tais como encontros de Agricultura Familiar, reuniões de conselhos municipais de meio ambiente, perante a Comissão de Direito Ambiental da OAB, dentre outros.

As exposições, que ocorreram em diversas cidades dos Campos Gerais e em Curitiba, procuraram contextualizar os diferentes aspectos relacionados à relevância da APA da Escarpa Devoniana e também o estado atual de ameaça iminente.

A estrutura básica das apresentações normalmente incluiu os seguintes tópicos:

- o Sistema Nacional de Unidades de Conservação;

- localização e características da região dos Campos Gerais e da Escarpa Devoniana, com ênfase nos atributos do patrimônio natural e cultural que demonstram o caráter especial da área;

- o decreto de criação da APA, seu Plano de Manejo e o Zoneamento Ecológico Econômico;

- demonstração dos diferentes valores da APA da Escarpa Devoniana, numa abordagem similar a de Gray (2004) ao detalhar os valores da geodiversidade (cultural, estético, econômico, funcional, didático e científico);

- ameaças à APA, incluindo crimes ambientais e um detalhamento do PL-527/2016;

- prejuízos (ambientais, econômicos, sociais, culturais etc.) com a aprovação da redução da APA;

- estratégias de defesa do patrimônio natural e cultural da APA da Escarpa Devoniana.

\section{Considerações Finais}

O projeto de lei mais polêmico dos últimos tempos no estado do Paraná, na área ambiental, sem dúvida é o de $\mathrm{n}^{\circ}$ 527, apresentado em 2016. A redução drástica da maior unidade de conservação em território paranaense mobilizou e uniu a comunidade científica, acadêmica, conservacionista e a população em geral em prol da APA da Escarpa Devoniana.

Há um lado positivo em toda a situação de retrocesso ambiental que essa questão envolve, ou seja, a notoriedade que a APA recebeu e o reconhecimento ou tomada de consciência por parte dos paranaenses de sua existência e do seu rico patrimônio natural. O uso de variados recursos de comunicação em diferentes mídias possibilitou o alcance de uma grande quantidade de pessoas e públicos. 'APA', 'Escarpa', 'Devoniana', palavras até então estranhas para a maioria da população, viraram até "hit" na voz das crianças.

Diversas moções de apoio foram aprovadas em favor da causa da APA da Escarpa Devoniana por entidades de classe e conselhos, durante encontros técnico-científicos ou por instituições, como foram os casos do IV Simpósio Brasileiro de Patrimônio Geológico e II Encontro Luso-Brasileiro de Patrimônio Geomorfológico e Geoconservação, do Conselho Estadual de Segurança Alimentar e Nutricional do Paraná, do Conselho Municipal de Meio Ambiente de Ponta Grossa, da Cáritas Brasileira Regional Paraná, da $6^{a}$ Conferência Estadual das Cidades do Paraná, dentre outras.

A exposição da situação de ameaça que a APA vem sofrendo, seja pelo PL-527/2016, seja pelo desrespeito ao seu Plano de Manejo, aliada à divulgação do conhecimento científico e ao debate sobre legislação e cidadania ambiental promoveu a participação popular no processo de decisão envolvendo o destino da UC. As ações mediadas por pesquisadores e entidades ambientais abriram espaço também para iniciativas espontâneas de cidadãos indignados com a questão, como a mobilização de alunos da rede pública com passeatas e aulas públicas, a inserção da causa nas ações da Campanha da Fraternidade de 2017 junto à comunidade católica da região dos Campos Gerais (a campanha teve como tema 'Fraternidade: biomas brasileiros e defesa da vida'), a realização da Ciclo-Tropa Pró-Escarpa, uma iniciativa de ciclistas que percorreram os municípios da APA, refazendo o caminho dos antigos tropeiros e chamando atenção para o 
potencial turístico e cultural dos Campos Gerais, dentre outras.

Essa participação da sociedade exerceu grande pressão sobre o legislativo paranaense, a ponto de um dos deputados autores do PL-527/2016, líder do governo na ALEP, retirar sua assinatura do documento e declarar publicamente que vai lutar contra sua aprovação. Outro deputado que assina a proposta (Presidente da ALEP) disse que o projeto não será votado sem um amplo debate. Tais fatos colaboraram para a estagnação do trâmite da proposta na ALEP, sem previsão de ir à votação em plenário.

A criação e a manutenção de unidades de conservação representam importantes mecanismos do poder público para garantir o direito constitucional do povo brasileiro ao meio ambiente ecologicamente equilibrado. No entanto são cada vez mais frequentes ações que colocam em risco a capacidade das UCs de efetivamente cumprir este papel. Chegar à sociedade a real importância da bio e geodiversidade destas áreas protegidas é também um grande desafio de comunicação. O exemplo aqui retratado da APA da Escarpa Devoniana pode servir de inspiração para situações similares em outros setores do território nacional.

\section{Referências}

Brasil. 2000. Lei n. 9.985, de 18 de julho de 2000. Regulamenta o art. 225, $\mathbb{\int} 1$ o, incisos I, II, III e VII da Constituição Federal, institui o Sistema Nacional de Unidades de Conservação da Natureza e dá outras providências. URL: http:// www.planalto.gov.br/ccivil_03/Leis/L9985.htm. Acesso 28.02.2018.

Brasil. 1988. Resolução Conama n. 10, de 14 de dezembro de 1988. Dispõe sobre a regulamentação das Áreas de Proteção Ambiental-APAs. URL: http://www.mma.gov.br/port/conama/legiabre. cfm?codlegi=74. Acesso 28.02.2018.

Gray M. 2004. Geodiversity: valuing and conserving abiotic nature. Chichester: Wiley. $434 \mathrm{p}$.

Guimarães G.B., Liccardo A., Piekarz G.F. 2013. A valorização cultural do patrimônio geológicomineiro do Paraná. Bol. Paran. Geoc., 70:41-52.

Guimarães G.B., Rocha C.H., Moro R.S., Liccardo A. 2017. Serviços geossistêmicos e a redução da APA da Escarpa Devoniana. In: IV Simp. Bras. Patrim. Geol. e II Enc. Luso-Bras. Patrim. Geomorf. e Geoconservação. Anais... Ponta Grossa: GUPE. p. 201-205.

IBGE - Instituto Brasileiro de Geografia e Estatística. 2017. Estimativas 2017 municípios. URL: https:// agenciadenoticias.ibge.gov.br/agencia-detalhede-midia.html? view $=$ mediaibge $\&$ catid $=2103 \&$ $\mathrm{id}=1328$. Acesso 28.02.2018.

Jasper F. 2015. Grande Curitiba e Campos Gerais "levam" 90\% do Paraná competitivo. Curitiba, Gazeta do Povo, 27.set.2015. Economia. URL: http://www.gazetadopovo.com.br/economia/ grande-curitiba-e-campos-gerais-levam-90-doparana-competitivo-3bibci0mfld44dnudy9dcjrxi. Acesso 28.02.2018

Mascia, M.B., Pailler S., Krithivasan R., Roshchanka V, Burns D., Mlotha M.J., Murray D.R., Peng N. 2014. Protected area downgrading, downsizing, and degazettement (PADDD) in Africa, Asia, and Latin America and the Caribbean, 1900-2010. Biological Conservation, 169:355-361.

Melo M.S.de, Guimarães G.B., Ramos A.F.de, Prieto C.C. 2007. Relevo e hidrografia dos Campos Gerais. In: Melo M.S.de, Moro R.S., Guimarães G.B. orgs. 2007. Patrimônio natural dos Campos Gerais do Paraná. Ponta Grossa: Ed. UEPG. p 48-58.

Melo M.S.de, Moro R.S., Guimarães G.B. orgs. 2017. Patrimônio natural dos Campos Gerais do Paraná. Ponta Grossa: Ed. UEPG. 230p.

MMA - Ministério do Meio Ambiente. 2004. Áreas prioritárias. URL: http://www.mma.gov.br/ biodiversidade/projetos-sobre-a-biodiveridade/ projeto-de-conserva $\%$ C3\%A7\%C3\%A3o-eutiliza\%C3\%A7\%C3\%A3o-sustent\%C3\%A1velda-diversidade-biol\%C3\%B3gica-brasileiraprobio-i/\%C3\%A1 reas-priorit\%C3\%A1rias. Acesso 28.02.2018.

MMA. Ministério do Meio Ambiente. 2015. A participação social e a ação pedagógica na implementação da unidade de conservação. URL: http://www.iicabr. iica.org.br/wp-content/uploads/2016/03/caderno2_A-participa\%C3\%A7\%C3\%A3o-social-e-aa\%C3\%A7\%C3\%A3o-pedag\%C3\%B3gica-naimplementa\%C3\%A7\%C3\%A3o-da-UC.pdf. Acesso 28.02.2018.

Moreira J.C, Rocha C.H. 2007. Unidades de Conservação nos Campos Gerais. In: Melo M.S.de, Moro R.S., Guimarães G.B. orgs. 2007. Patrimônio natural dos Campos Gerais do Paraná. Ponta Grossa: Ed. UEPG. p. 201-212.

OJC. Observatório de Justiça e Conservação. 2018. Vídeo clipe em defesa da maior Área de Proteção Ambiental do Sul do Brasil ganha versão em libras e legendas. Curitiba, 15 fev. 2018. Notícias. URL: http://www. justicaeco.com.br/noticias/video-clipe-em-defesada-maior-area-de-protecao-ambiental-do-sul-dobrasil-ganha-versao-em-libras-e-legendas/. Acesso 28.02.2018.

Paraná. 1992. Decreto n. 1231, de 27 de março de 1992. Declaração da Área de Proteção Ambiental para assegurar a proteção do limite natural entre os planaltos paranaense e locais de beleza cênica e de vestígios arqueológicos e pré-históricos. URL: http://celepar7.pr.gov.br/sia/atosnormativos/form cons_ato1.asp?Codigo =1741. Acesso 28.02.2018.

Scalco R.F, Gontijo B.M. 2017. Possibilidades de desafetação e recategorização em Unidades de Conservação de proteção integral: as UCs da porção central do Mosaico do Espinhaço (Minas Gerais/Brasil). Revista da Anpege, 13(22):247-276.

Silva M.G.da. 2014. Área de proteção que corta o estado ganha novo mapa. Curitiba, Gazeta do Povo, 02.ago.2014. Vida e Cidadania. URL: http:// www.gazetadopovo.com.br/vida-e-cidadania/

\begin{tabular}{c|c|c|c|c|c}
\hline (C) Terrae Didat. & Campinas, SP & v.14 & n.4 & p. 455-462 & out./dez. 2018 \\
\hline
\end{tabular}


area-de-protecao-que-corta-o-estado-ganhanovo-mapa-ebncxy8r3gz21vj78krorjj9q. Acesso 28.02.2018.

Souza C.R.G., Souza A.P. 2002. O Escarpamento Estrutural Furnas, SP/PR - Raro sítio geomorfológico brasileiro. In: Schobbenhaus C., Campos D.A., Queiroz E.T., Winge M., BerbertBorn M. orgs. 2002. Sítios geológicos e paleotológicos do Brasil. Brasília: DNPM. p. 299-306.

Symes W.S., Rao M., Mascia M.B., Carrasco L.R.
2016. Why do we lose protected areas? Factors influencing protected area downgrading, downsizing and degazettement in the tropics and subtropics. Global Change Biology, 22:656-665.

Weirich Neto P.H., Rocha C.H. 2007. Caracterização da produção agropecuária e implicações ambientais nos Campos Gerais. In: Melo M.S.de, Moro R.S., Guimarães G.B. orgs. 2007. Patrimônio natural dos Campos Gerais do Paraná. Ponta Grossa: Ed. UEPG. p. 181-190. 